\title{
The Secretion of Classical and Peptide Cotransmitters from a Single Presynaptic Neuron Involves a Synaptobrevin-Like Molecule
}

\author{
Matthew D. Whim, ${ }^{1}$ Heiner Niemann, ${ }^{2}$ and Leonard K. Kaczmarek ${ }^{1}$ \\ ${ }^{1}$ Department of Pharmacology, Yale University School of Medicine, New Haven, Connecticut 06520-8066, and 2Federal \\ Research Center for Virus Diseases of Animals, D-72076 Tübingen, Germany
}

\begin{abstract}
It is not yet understood how the molecular mechanisms controlling the release of neuropeptides differ from those controlling the release of classical transmitters, mainly because there are few peptidergic synapses in which the environment at the presynaptic release sites can be manipulated. Using Aplysia californica neuron B2, which synthesizes both peptide and classical transmitters, we have established two synaptic types. When B2 is cocultured with a sensory neuron, a peptidergic synapse is formed. In contrast, when B2 is cocultured with
\end{abstract}

neuron B6, a classical synapse is formed. In contrast to a common assumption, single action potentials can release both types of transmitters. The secretion of peptide and classical transmitters by B2 is inhibited by the presynaptic injection of tetanus toxin, but not by an inactive mutant. Thus a synaptobrevin-like molecule is involved in the secretion of these two types of transmitters.

Key words: neuropeptide; classical transmitter; neurotransmission; synapse; synaptobrevin; synaptic vesicle protein
Many neurons, perhaps all, contain classical and peptide cotransmitters (Kupfermann, 1991). Although there are similarities in the secretion of the two types of transmitters, differences are known. For example, the release of classical transmitters occurs with a single action potential, whereas secretion of peptides can require high frequency firing or a particular pattern of activity (Dutton and Dyball, 1979; Jan and Jan, 1982; Whim and Lloyd, 1989; Cropper et al., 1990b; Peng and Horn, 1991). In addition, the relationship between transmitter release and intracellular calcium apparently differs between the two transmitter types (Dodge and Rahamimoff, 1967; Peng and Zucker, 1993). Finally, although clear vesicles that contain classical transmitters are clustered at release sites, peptide secretion does not occur at a well defined active zone (De Camilli and Jahn, 1990).

Whereas many proteins likely to be important in the secretion of synaptic vesicles have been identified, comparatively little is known about their specific roles in transmitter secretion, particularly of neuropeptides. One protein that seems to be essential for the release of classical transmitters is synaptobrevin (also known as VAMP: vesicle-associated membrane protein), a protein for which two isoforms are known and which is expressed in neurons and other secretory cells (Trimble et al., 1988; Elferink et al., 1989; Cain et al., 1992). Synaptobrevin interacts with other nerve terminal proteins to form complexes that may mediate vesicle docking and fusion (Sollner et al., 1993). Investigations of the physiological role of synaptobrevin have profited from the discovery that tetanus toxin, an inhibitor of neurotransmitter release, is a protease that selectively digests synaptobrevin 1 and 2 (Schiavo et al., 1992; Niemann et al., 1994).

Evidence also exists for the involvement of the synaptobrevins

Received Dec. 4, 1996; revised Jan. 15, 1997; accepted Jan. 21, 1997.

This work was supported by Grant NS-18492 from National Institutes of Health to L.K.K. We thank Drs Si-Qiong Liu and Benjamin White for critically reading this manuscript.

Correspondence should be addressed to Dr. Matthew D. Whim, Department of Pharmacology, Yale University School of Medicine, 333 Cedar Street, New Haven, CT 06520-8066.

Copyright (C) 1997 Society for Neuroscience $\quad 0270-6474 / 97 / 172338-10 \$ 05.00 / 0$ in the release of dense core granules, some of which may contain peptides (Penner et al., 1986; Dayanthi et al., 1994; Bruns and Jahn, 1995). However, most studies have used nonpeptidergic or nonsynaptic models. It is not clear whether synaptobrevin is involved in the synaptic secretion of neuropeptides.

A major difficulty in studying neuropeptide release has been that there are very few synaptic responses that have been demonstrated to be attributable to the release of neuropeptides and in which it is possible to record both pre- and postsynaptically (but see Willard, 1990). This criterion is important because it allows the selective presynaptic injection of probes of transmitter release. We therefore sought to produce a synapse from which we could monitor the release of an identified neuropeptide reliably. We used motor neurons B1 or B2 from Aplysia as the peptidereleasing cell. These neurons synthesize and release the small cardioactive peptides A and B (SCPs; Lloyd et al., 1986), which are localized to dense core granules in both cells (Reed et al., 1988). In addition, B2 is thought to be cholinergic (Lloyd et al., 1985). Using different postsynaptic targets, we have measured the release of both peptide and classical transmitters. Our data indicate that a synaptobrevin-like protein is involved in both types of neurotransmission.

\section{MATERIALS AND METHODS}

Cell culture. Cells were isolated and maintained via standard techniques (Schacher and Proshansky, 1983). Briefly, buccal and pedal-pleural ganglia from Aplysia californica ( $\sim 5$ and $\sim 150 \mathrm{gm}$, respectively) were incubated in $1 \%$ protease (Sigma type IX, Sigma, St. Louis, MO) in sterile normal artificial seawater (nASW) at $34^{\circ} \mathrm{C}$ for 2 or $3 \mathrm{hr}$, respectively. Neurons were removed by using finely pulled glass probes and maintained in sterile culture medium [30\% Aplysia hemolymph: 70\% ASW containing penicillin $(50 \mathrm{U} / \mathrm{ml})$, streptomycin $(50 \mu \mathrm{g} / \mathrm{ml})$, vitamins $(0.5 \times \mathrm{MEM})$, and nonessential $(0.2 \times$ MEM $)$ and essential amino acids without L-glutamine $(0.2 \times \mathrm{MEM})]$ at room temperature. Neurons generally could be identified by visual criteria alone (Church et al., 1993; Whim and Lloyd, 1994), and any anomalous ganglia were rejected.

Two synaptic configurations were used, depending on the type of synapse required. In most experiments in which peptide release was monitored, the presynaptic B1 or B2 neurons were plated individually into poly-L-lysine-coated culture dishes (Falcon 1006, Falcon, Oxnard, 
CA). After $2 \mathrm{~d}$, during which the neuron had grown an extensive neuritic tree, a single pleural sensory neuron was manipulated onto the neuritic tree. Synapses generally were used within $24 \mathrm{hr}$ before significant postsynaptic growth had occurred. This improved the conditions for voltage clamp. The second configuration enabled synapses to form between isolated somata. All of the experiments in which the release of ACh was monitored used this soma $\rightarrow$ soma synapse (see Haydon, 1988). Briefly, the presynaptic B2 and the postsynaptic B6 neurons were isolated and separately maintained in droplets of culture medium on dishes made nonadherent by coating them with 5\% BSA. After $24 \mathrm{hr}$ the primary neurite had been reabsorbed, and the pre- and postsynaptic cells were juxtaposed in a soma $\rightarrow$ soma configuration. The neurons rapidly adhered to each other and were used within 1-7 d. In some experiments B3 was used as the ACh detector cell (because it also receives a cholinergic IPSP; Gardner, 1971). No differences were observed between experiments using B3 and B6. For recording, the cell pair was transferred to a poly-L-lysinecoated culture dish. In some experiments the release of the SCPs also was monitored in a soma $\rightarrow$ soma synapse. In these experiments the presynaptic cell was either B1 or B2, whereas the postsynaptic cell was a single pleural sensory neuron. Most experiments were performed in nASW containing (in mM): $460 \mathrm{NaCl}, 10.4 \mathrm{KCl}, 55 \mathrm{MgCl}_{2}, 11 \mathrm{CaCl}_{2}$, and 15 HEPES, $\mathrm{pH}$ 7.8. Some experiments made use of a low $\mathrm{Ca}^{2+}(0.5 \mathrm{~mm}) /$ high $\mathrm{Mg}^{2+}(110 \mathrm{~mm})$ ASW.

Neuron terminology. In the present experiments in which peptide release was measured from neurons B1 and B2, no differences were seen between the two cells (see also Whim and Lloyd, 1994); for simplicity in the text they are referred to collectively as B1,2. For each figure the individual neuron is identified. For the experiments studying the release of ACh, only B2 neurons were used.

Electrical recordings. Pre- and postsynaptic recordings were made with two Axoclamp 2A amplifiers (Axon Instruments, Foster City, CA) that were "linked" electronically to reduce coupling artifacts. Each cell was impaled with a single microelectrode $(5-10 \mathrm{M} \Omega$ ) filled with $2 \mathrm{M}$ potassium acetate, $0.5 \mathrm{~m} \mathrm{KCl}$, and $10 \mathrm{~mm}$ HEPES, $\mathrm{pH}$ 7.2. Before impalement the tips were dipped into Sigmacoat (Sigma), which significantly improved the quality of the recordings. The presynaptic cell was held under current clamp in either bridge or discontinuous current-clamp (DCC) mode while the postsynaptic cell was voltage-clamped with the switching voltageclamp technique. Voltage-clamp gain was generally $0.3-0.8 \mathrm{nA} / \mathrm{mV}$, and switching frequencies of $5 \mathrm{kHz}$ were obtained routinely. Membrane current was filtered at $20 \mathrm{~Hz}$ to $2 \mathrm{kHz}$, and recordings were stored on tape. Voltage protocols were generated with Indec BASIC-FASTLAB software (Sunnyvale, CA). In early experiments in which the presynaptic cell was recorded in DCC mode (see Figs. 2 and 5), transients were apparent in the postsynaptic records, which were phase-locked to the presynaptic spikes. These arose as coupling artifacts between the two amplifiers and were reduced in later recordings made in bridge mode.

Cell injections. Injections were made with brief pressure pulses (3-20 $\mathrm{msec}$ ) with a Picospritzer (General Valve, Fairfield, NJ) and an injection pressure of 14 psi. Microelectrodes had tip diameters of $\sim 1 \mu \mathrm{m}$. Recombinant tetanus toxin and the inactive tetanus toxin mutant were prepared as described (Yamasaki et al., 1994) and stored in aliquots at $-80^{\circ} \mathrm{C}$. Toxin $(12 \mu \mathrm{M})$ was injected in a solution containing $0.5 \%$ fast green, $1 \mathrm{~mm}$ dithiothreitol, $5 \mathrm{~mm}$ HEPES, and $75 \mathrm{~mm}$ potassium glutamate, $\mathrm{pH}$ 7.2. For the purposes of statistical analysis, comparisons between treatments were made by a two-tailed Student's $t$ test.

\section{RESULTS}

\section{Stimulation of B1,2 neurons induces a slow inward current in the postsynaptic sensory neuron}

To establish cocultures of peptidergic neurons with postsynaptic targets, we cultured single B1 or B2 neurons from the buccal ganglia of Aplysia with single sensory neurons from the pleural ganglia. Exogenous application of the SCP neuropeptides has been shown to evoke an inward current in these sensory neurons (Ocorr and Byrne, 1985). The sensory neurons were placed onto the neurites of the B1,2 neurons (see Materials and Methods for neuron terminology) after $2 \mathrm{~d}$ in culture, at which time the peptidergic $\mathrm{B} 1,2$ neurons had regenerated a large neuritic tree (Fig. 1A).

Stimulation of a presynaptic B1,2 neuron with depolarizing current pulses triggered action potentials (for which the duration
A

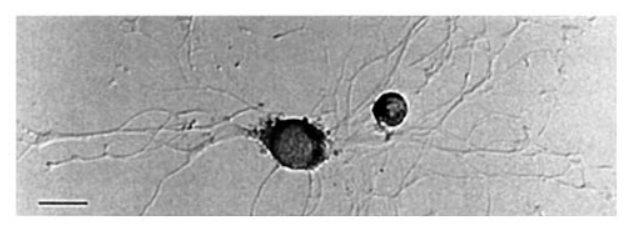

B

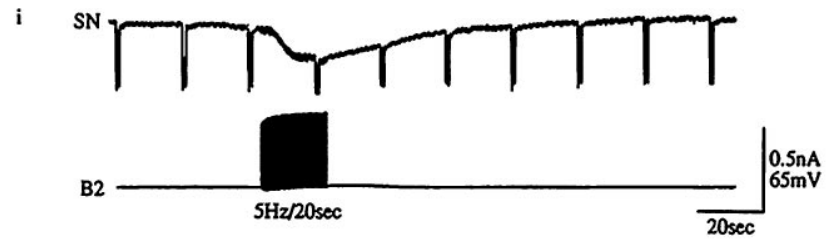

ii

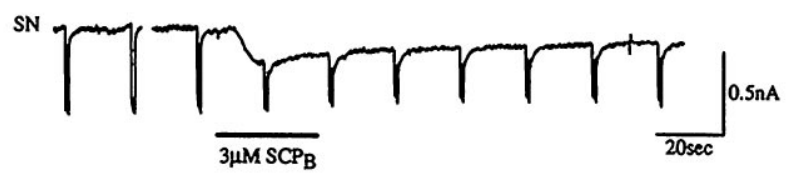

C
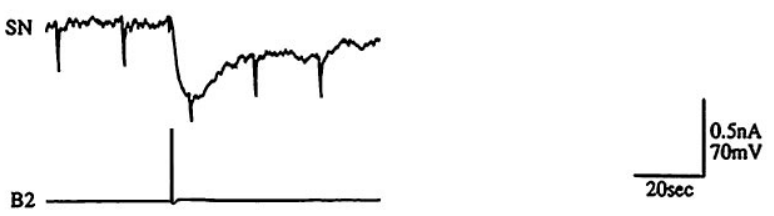

Figure 1. $\mathrm{B} 1,2$ stimulation and $\mathrm{SCP}_{\mathrm{B}}$ application evoke a slow current in the postsynaptic neuron associated with a decrease in membrane conductance. $A$, Bright-field image of a presynaptic B1 neuron (at left) with associated neuritic tree and a postsynaptic sensory neuron. Scale bar, 80 $\mu \mathrm{m}$. Bi, Stimulation of B2 at $5 \mathrm{~Hz}$ for $20 \mathrm{sec}$ evoked a slow inward current in the sensory neuron. The sensory neuron was voltage-clamped at a holding potential of $-40 \mathrm{mV}$, and $10 \mathrm{mV}$ hyperpolarizing steps were applied at $20 \mathrm{sec}$ intervals. Bii, Bath application of $3 \mu \mathrm{M} \mathrm{SCP}$ (indicated by black bar) evoked a slow inward current in the sensory neuron. $C$, In a different cell pair, a single B2 spike elicited a slow inward current in the postsynaptic sensory neuron, which was voltaged-clamped at $-40 \mathrm{mV}$ and hyperpolarized by $2 \mathrm{mV}$ every $20 \mathrm{sec}$.

at $50 \%$ amplitude was $3.5 \mathrm{msec} \pm 1.1$; mean $\pm \mathrm{SD}, n=7$ ). These action potentials evoked a slow inward current in the postsynaptic sensory neuron when the latter was voltage-clamped at a holding potential of $-40 \mathrm{mV}$ (Fig. 1 Bi). The inward current outlasted the period of B1,2 stimulation. Recordings of the activity of B1,2 in the freely behaving animal have indicated that these cells fire at frequencies at $\sim 3 \mathrm{~Hz}$ for up to $3 \mathrm{sec}$ during ingestion of food (Lloyd et al., 1988). The postsynaptic inward current progressively increased when cells were stimulated by frequencies within this range.

To determine the change in conductance during the slow inward current, we stepped the postsynaptic membrane potential at regular intervals from -40 to $-50 \mathrm{mV}$. The decrease in the size of the current steps during the synaptic current indicated an apparent decrease in membrane conductance (Fig. 1Bi). Bath application of $3 \mu \mathrm{M} \mathrm{SCP}{ }_{\mathrm{B}}$ also evoked a slow inward current, with an associated decrease in membrane conductance (Fig. 1Bii).

Although, as is typical for many peptidergic neurons, the amplitude of the postsynaptic current increased during trains of action potentials, in some preparations a single action potential was sufficient to induce a slow synaptic current. This was observed 
A

i

ASW
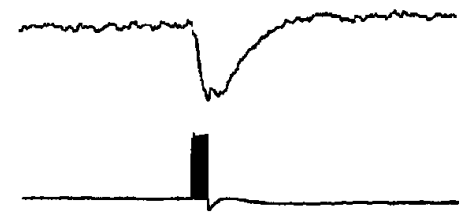

ii

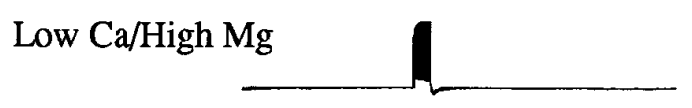

iii $\mathrm{SN}$

ASW

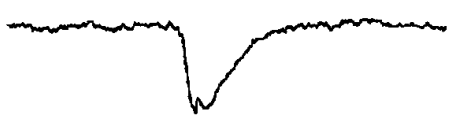

B1
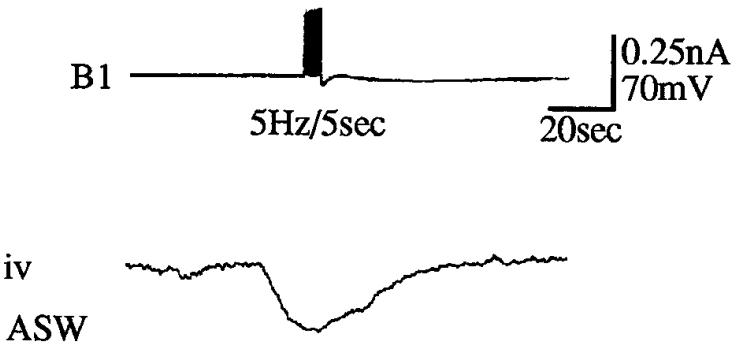

ASW
B

i

ASW

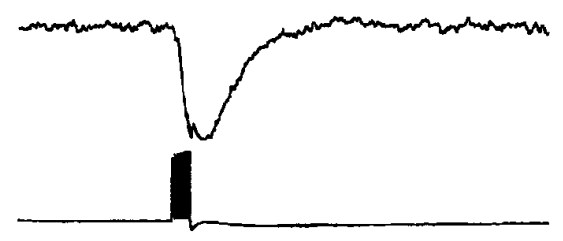

ii

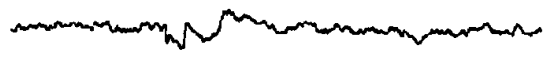

$0.1 \mu \mathrm{M} \mathrm{SCP}_{\mathrm{B}}$

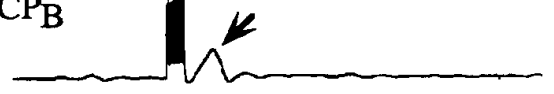

ASW

B1
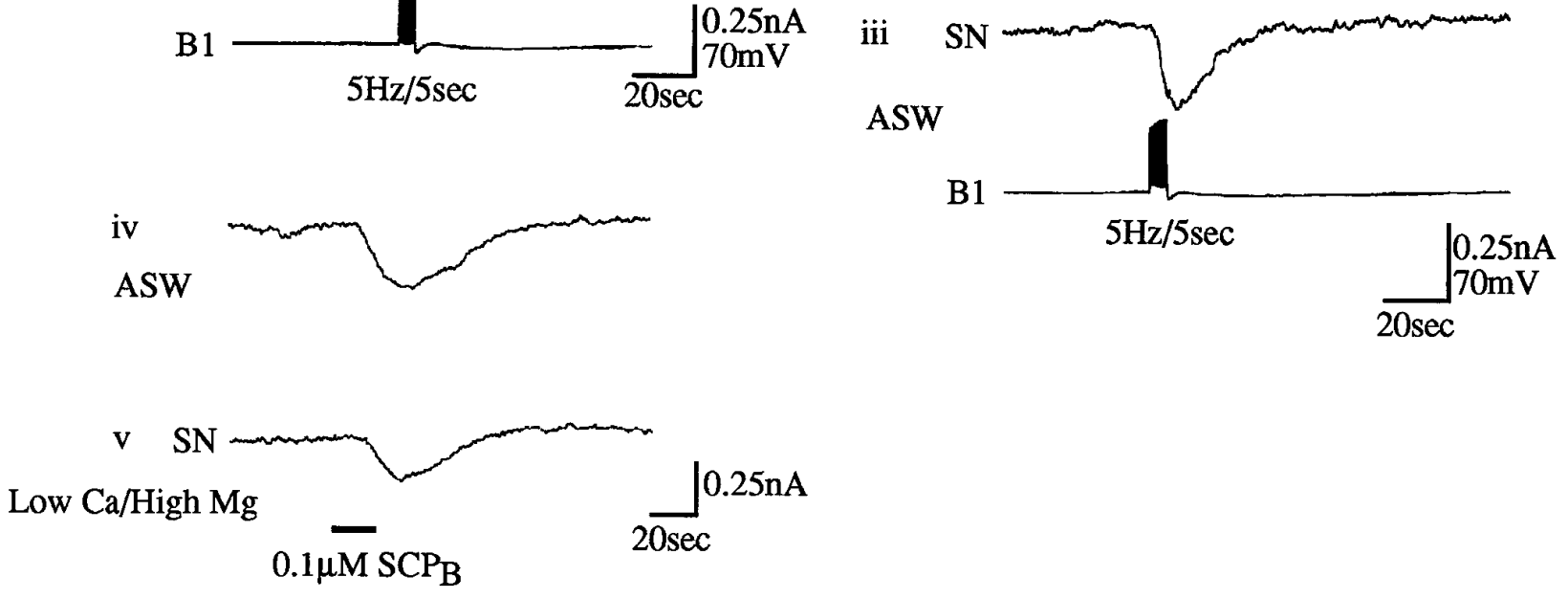

Figure 2. The postsynaptic current evoked by B1,2 stimulation is calcium-dependent and is desensitized by exogenous SCPs. $A$ i, Stimulation of B1 at 5 $\mathrm{Hz}$ for $5 \mathrm{sec}$ in nASW evoked a slow inward current in the postsynaptic sensory neuron, which was voltage-clamped at a holding potential of $-40 \mathrm{mV}$. Aii, When the bathing solution was changed to a low $\mathrm{Ca}^{2+} /$ high $\mathrm{Mg}^{2+}$ ASW $\left(0.5 \mathrm{~mm} \mathrm{Ca}{ }^{2+} / 110 \mathrm{~mm} \mathrm{Mg}^{2+}\right)$, the synaptic current could not be evoked, but (Aiii) could be elicited again when the bath solution was returned to nASW. The notch in the synaptic current was an artifact caused by electrical coupling between pre- and postsynaptic electrodes (individual transients are not visible because of filtering). Bath application of $0.1 \mu \mathrm{M} \mathrm{SCP} \mathrm{B}_{\mathrm{B}}$ evoked a slow inward current in the sensory neuron in (Aiv) nASW and $(A v)$ low $\mathrm{Ca}^{2+} /$ high $\mathrm{Mg}^{2+}$ ASW. B, Desensitization of SCP receptors blocked the synaptic current. Bi, In nASW, stimulation of B1 at $5 \mathrm{~Hz}$ for $5 \mathrm{sec}$ evoked a slow synaptic current in the postsynaptic sensory neuron, which was voltage-clamped at a holding potential of $-40 \mathrm{mV}$. Bii, Continuous application of $0.1 \mu \mathrm{M} \mathrm{SCP}$ 作 $10 \mathrm{~min}$ desensitized the postsynaptic SCP receptors (see Results). In these conditions stimulation of B1 no longer evoked a synaptic current. Note the slow presynaptic depolarization (arrow) that occurred after B1 stimulation. Biii, After extensive washing in nASW, stimulation of B1 again evoked a slow synaptic current. The notch in the synaptic current reflects coupling between the preand postsynaptic electrodes (individual transients are not visible because of filtering). $A$ and $B$ are from different cell pairs.

most frequently (in $\sim 50 \%$ of preparations) when a synapse was made between two opposed cell bodies (see Materials and Methods). This may indicate that under these conditions the synapses are concentrated in a relatively small area. The synaptic delay after a single action potential was $1.18 \mathrm{sec} \pm 1.02$ (mean $\pm \mathrm{SD}$, $n=5$ ). Part of this delay presumably reflects the fact that peptides are not released at specialized zones but diffuse to the site of action. In addition, the postsynaptic actions of the SCPs are mediated via a second messenger (Abrams et al., 1984). A similar decrease in membrane conductance to that observed during re- petitive stimulation also was observed during the current evoked by a single action potential (Fig. $1 C$ ).

\section{Induction of the synaptic current is calcium-dependent}

The synaptic current induced by stimulation of B1,2 neurons in nASW (Fig. 2Ai) was blocked by lowering the concentration of calcium and raising that of magnesium in the bathing medium (Fig. 2Aii). The synaptic current could be evoked again when nASW was reintroduced (Fig. 2Aiii). Bath application of a low concentration of $\mathrm{SCP}_{\mathrm{B}}$ evoked a slow postsynaptic current in both 
nASW and low $\mathrm{Ca}^{2+} /$ high $\mathrm{Mg}^{2+}$ ASW (Fig. 2Aiv,v), indicating that the elimination of the synaptic current in the low $\mathrm{Ca}^{2+} /$ high $\mathrm{Mg}^{2+}$ ASW was likely to be attributable to an action at a presynaptic site. Thus the induction of the synaptic current involved the release of transmitter and was mimicked by the exogenous application of the SCPs (although $\mathrm{SCP}_{\mathrm{B}}$ generally was used, the SCPs are equipotent in all preparations examined; Lloyd et al., 1985). The following experiments were then designed to test directly whether the synaptic current was attributable to the release of the SCPs.

\section{The synaptic current is desensitized by exogenous SCPs}

If the slow synaptic current results from the release of the SCPs, it should be possible to block the current by desensitizing the postsynaptic SCP receptors. $\mathrm{SCP}_{\mathrm{A}}$ and $\mathrm{SCP}_{\mathrm{B}}$ have similar sequences, and the responses to these two peptides crossdesensitize. Their effects thus are thought to be mediated by a single receptor (Abrams et al., 1984).

A synaptic current was evoked by stimulation of the presynaptic B1,2 neuron (Fig. 2Bi). Bath application of $0.1 \mu \mathrm{M} \mathrm{SCP}$ B then induced an inward current in the sensory neuron. In the continued presence of peptide, this current slowly recovered toward the control level. Desensitization typically took $\sim 10 \mathrm{~min}$ in the continuous presence of peptide, after which subsequent stimulation of B1,2 no longer evoked a synaptic current (Fig. 2Bii). After prolonged washout of exogenous $\mathrm{SCP}_{\mathrm{B}}$, the synaptic current could be evoked again by presynaptic stimulation (Fig. 2Biii). Similar results were seen in five experiments.

The inhibition of the synaptic current in response to application of the SCPs was not attributable to a reduction of presynaptic excitability. Previous work has shown that the release of radiolabeled SCPs from B1,2 neurons is unaffected by the presence of exogenous SCPs (Whim and Lloyd, 1992). Moreover, B1,2 neurons were hyperexcitable in the presence of $\mathrm{SCP}_{\mathrm{B}}$, as evidenced by the slow presynaptic depolarization that occurred in these conditions (Fig. 2Bii, arrow). Thus the inhibition of the slow synaptic current in the presence of $\mathrm{SCP}_{\mathrm{B}}$ is likely to be attributable to a desensitization of the postsynaptic receptor for the SCPs rather than to an inhibition of peptide release.

\section{The synaptic- and $\mathrm{SCP}_{\mathrm{B}}$-induced currents have the same null potential}

To determine the null potential of the synaptic current evoked by stimulation of the presynaptic B1,2 neuron, we stepped the postsynaptic membrane potential from $-30 \mathrm{mV}$ to $-70 \mathrm{mV}$ in 5 $\mathrm{mV}$ increments before and at the peak of the synaptic current. Similar measurements were made before and at the peak of the current induced by the exogenous application of $0.1 \mu \mathrm{M} \mathrm{SCP} \mathrm{B}_{\mathrm{B}}$ to the same synaptically coupled cell pair. The resulting $I-V$ traces for one cell pair are shown in Figure $3 A$. Then the net induced current (i.e., the difference current) was calculated for both the synaptic- and $\mathrm{SCP}_{\mathrm{B}}$-evoked currents. The voltage dependence and null potential of the difference currents were very similar, and some rectification was observed for both (Fig. 3B). Similar results were obtained in four synapses. The null potential for the synaptic current from four cell pairs was $-54 \mathrm{mV} \pm 3.4$ (mean $\pm \mathrm{SD}$ ), whereas the null potential for the $\mathrm{SCP}_{\mathrm{B}}$-induced current was -54 $\mathrm{mV} \pm 5.9$ (mean $\pm \mathrm{SD}$ ). The slow synaptic currents induced by repetitive stimulation or by a single action potential showed the same voltage dependence (data not shown).
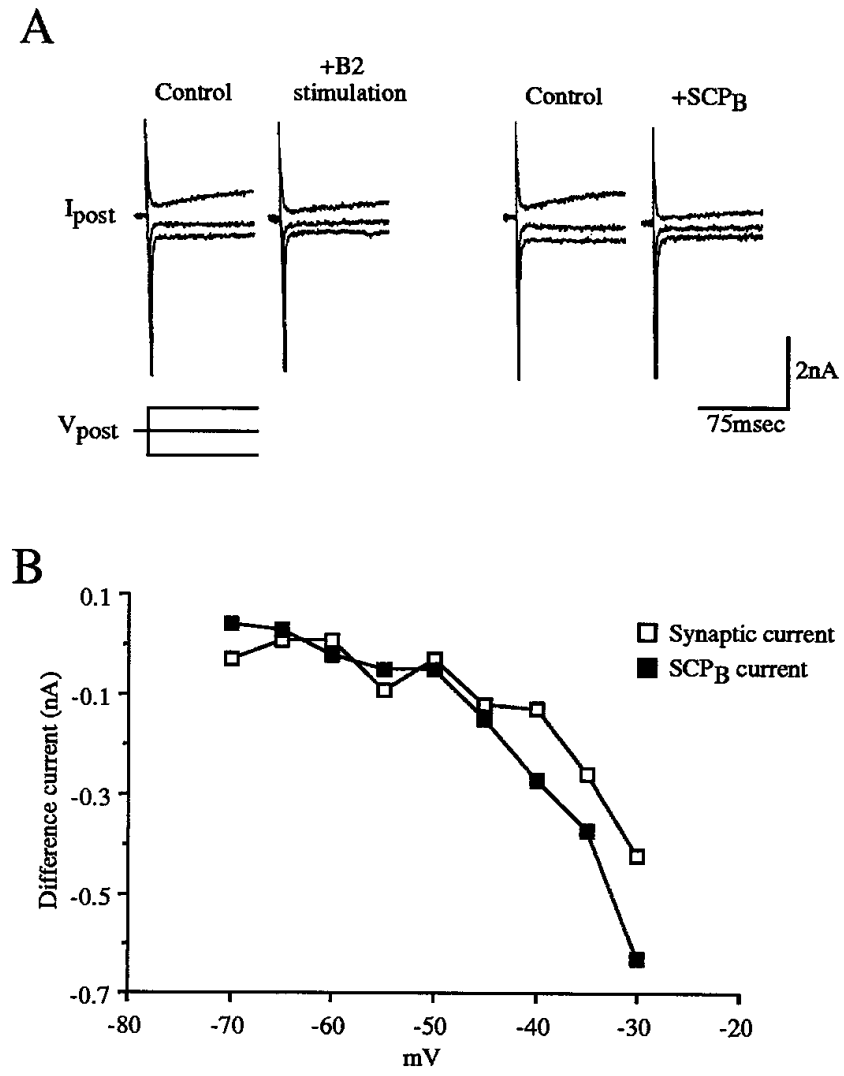

Figure 3. The synaptic- and $\mathrm{SCP}_{\mathrm{B}}$-induced currents have a similar voltage dependence. $A$, Current-voltage relationships were measured in a postsynaptic sensory neuron before (Control) and at the peak of the synaptic current evoked by stimulation of $\mathrm{B} 2$ at $5 \mathrm{~Hz}$ for $15 \mathrm{sec}(+B 2$ stimulation $)$ and before (Control) and at the peak of the current evoked by bath application of $0.1 \mu \mathrm{M} \mathrm{SCP} \mathrm{B}_{\mathrm{B}}\left(+S C P_{B}\right)$. The records show the membrane current recorded in response to voltage steps to $-30 \mathrm{mV}$ (top traces), $-50 \mathrm{mV}$ (middle traces), and $-70 \mathrm{mV}$ (bottom traces). The holding voltage was $-40 \mathrm{mV}$. $B$, The difference currents for both the synaptic- and $\mathrm{SCP}_{\mathrm{B}}$-induced currents show a similar voltage dependence and null potential. $A$ and $B$ are from the same experiment.

\section{$\mathrm{SCP}_{\mathrm{B}}$ application and synaptic stimulation produce antiaccommodation in the postsynaptic sensory neuron}

When a depolarizing current pulse $(500 \mathrm{msec})$ is applied to the postsynaptic sensory neuron in a synaptic pair, a single action potential is evoked at the onset of the pulse. In the presence of a low concentration of $\mathrm{SCP}_{\mathrm{B}}$ the same depolarization evokes multiple action potentials (Fig. $4 A$ ). This behavior has been termed "antiaccommodation" and is believed to be attributable to the inhibition of a potassium conductance that is open at the resting potential (Klein et al., 1986). If the SCPs are released synaptically, then stimulation of the presynaptic B1,2 neuron also should evoke antiaccommodation in the sensory neuron. This is indeed what we observed. In the experiment illustrated in Figure 4, when the presynaptic B1 neuron was stimulated at $5 \mathrm{~Hz}$ for $15 \mathrm{sec}$ (a paradigm that induced a synaptic current in this cell pair; data not shown), the number of action potentials evoked by the depolarizing pulse was increased from one to five (Fig. $4 B$ ). Both the response to exogenous $\mathrm{SCP}_{\mathrm{B}}$ application and $\mathrm{B} 1$ stimulation readily reversed. Similar results were observed in three other experiments. Thus both $\mathrm{B} 1,2$ stimulation and $\mathrm{SCP}_{\mathrm{B}}$ application produce antiaccommodation in the postsynaptic sensory neuron. 
Control

A

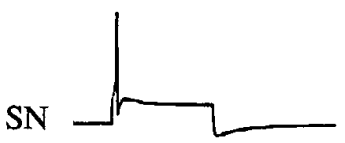

$\mathrm{B}$
Superfuse
$0.1 \mu \mathrm{M} \mathrm{SCP}$
$\mathrm{B}$

Peak of

response
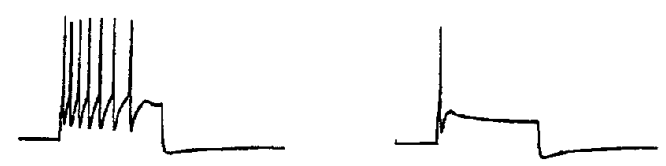
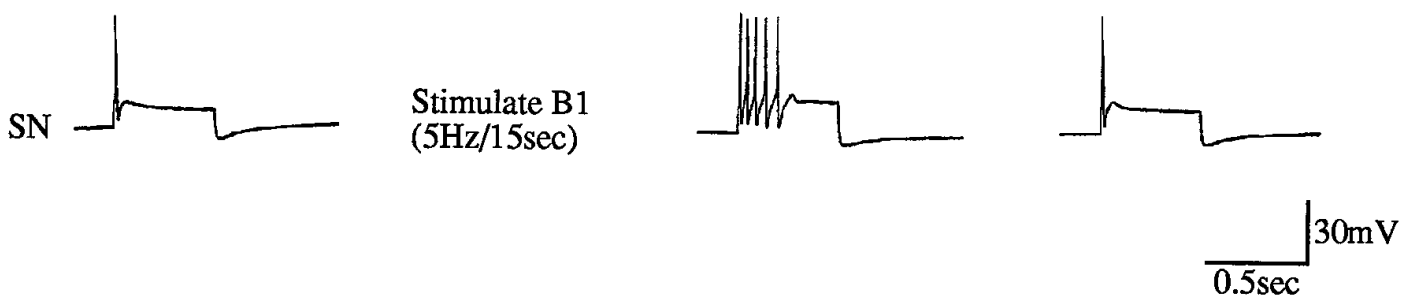

Figure 4. $\mathrm{B} 1,2$ stimulation and $\mathrm{SCP}_{\mathrm{B}}$ application both produce anti-accommodation in the postsynaptic sensory neuron. $A$, Depolarization of the sensory neuron for $500 \mathrm{msec}$ evoked a single action potential (Control). After bath application of $0.1 \mu \mathrm{M} \mathrm{SCP}{ }_{\mathrm{B}}$, the same depolarization evoked seven action potentials in the sensory neuron (Peak of response). Recovery was seen after washout of $\mathrm{SCP}_{\mathrm{B}}$. B. Same protocol as in $A$, but after a control depolarization (Control) B1 was stimulated at $5 \mathrm{~Hz}$ for $15 \mathrm{sec}$, after which depolarization of the sensory neuron now evoked five action potentials (Peak of response). After washout, each depolarization again evoked one action potential. The sensory neuron was maintained at a holding potential of $-40 \mathrm{mV}$ throughout the experiment by injecting a variable amount of hyperpolarizing current.

\section{The synaptic current does not contain a significant cholinergic component}

In addition to releasing the SCPs, neuron B2 is thought to be a cholinergic neuron on the basis of its choline acetyltransferase activity (Lloyd et al., 1985). To determine whether the synaptic current evoked by B2 stimulation involved the release of acetylcholine (ACh), we examined the response of the sensory neurons to local application of $100 \mu \mathrm{M}$ ACh. When ACh was applied to the sensory neuron in a synaptically coupled cell pair, it evoked an outward current (Fig. 5Ai). This current was blocked in the presence of $500 \mu \mathrm{M}$ phenyltrimethylammonium (PTMA; Fig. 5Aii), an antagonist of the "slow IPSP" ACh receptor in Aplysia (Kehoe, 1972a). However, in the same synaptic pair PTMA did not markedly affect the slow synaptic current evoked by stimulation of $\mathrm{B} 2$ at $2 \mathrm{~Hz}$ for $10 \mathrm{sec}$ (Fig. $5 B$ ). Similar results were observed at three synapses. These results indicate that the slow inward current does not include a significant cholinergic component.

Because neuron B2 is believed to be cholinergic, these findings raise the question as to why a cholinergic component was not observed. One possibility is that released peptide modulated the postsynaptic ACh receptor. Consistent with this suggestion, we noted that the response of the sensory neuron to the puffed application of ACh was attenuated in the presence of exogenous $\mathrm{SCP}_{\mathrm{B}}$ (Fig. 5C). This effect was observed consistently. In six cells the response to $100 \mu \mathrm{M}$ ACh was significantly depressed to $44 \pm$ $15 \%$ of its control value in the presence of $1 \mu \mathrm{M} \mathrm{SCP} \mathrm{B}_{\mathrm{B}}$ (mean \pm $\mathrm{SD}, p<0.001)$. Because $\mathrm{B} 2$ often fires spontaneously in culture (Whim and Lloyd, 1994), the released SCPs therefore may have resulted in a chronic depression of the ACh response at the postsynaptic membrane. Other explanations include the possibility that the ACh receptors are not clustered under the sites of transmitter release (Anderson et al., 1977).

\section{Presynaptic neuron B2 releases ACh}

Although the secretion of ACh from B2 could not be detected by using a pleural sensory neuron, we examined whether other neurons might be able to monitor the release of ACh. For these experiments we used neurons B6 or B3, because both receive a cholinergic IPSP in situ (Gardner, 1971). In the experiment shown in Figure 6, when B2 was combined with buccal neuron B6 in a soma $\rightarrow$ soma configuration (Fig. 6A), single presynaptic action potentials evoked a rapid outward current in B6 when the latter was voltage-clamped at $-40 \mathrm{mV}$ (Fig. 6 Bi). The synaptic current was eliminated in a low $\mathrm{Ca}^{2+} /$ high $\mathrm{Mg}^{2+} \mathrm{ASW}$ (data not shown) and was blocked completely in the presence of D-tubocurarine and PTMA (Fig. 6Bii), antagonists of the "rapid" and "slow" IPSPs in Aplysia neurons, respectively (Kehoe, 1972a). Similarly, local application of ACh from a puffer pipette onto the B6 neuron in the same synaptic pair also evoked an outward current, which was blocked by the combination of D-tubocurarine and PTMA (Fig. 6Cii). Interestingly, the synaptic current was eliminated completely by D-tubocurarine, but not by PTMA, whereas the response to the application of ACh was blocked only in the presence of both antagonists (data not shown). As a control for specificity, when B1 (a noncholinergic neuron) was combined with neuron B6 (or B3) in a soma $\rightarrow$ soma configuration, a single B1 action potential did not evoke a rapid outward current in the postsynaptic neuron $(n=2)$.

To confirm further that the outward current at these synapses was elicited by ACh release and not by release of the SCPs, we tested the response of B6 and B3 to bath-applied SCPs. In the cell pair shown in Figure $6 B-D, \mathrm{SCP}_{\mathrm{B}}$ produced a biphasic response: an early inward current followed by a later outward current. Neither phase was markedly affected by D-tubocurarine and PTMA (Fig. 6Dii). We conclude that the outward synaptic current produced in response to a single action potential in neuron B2 
A

Response to ACh puffs

i

ASW

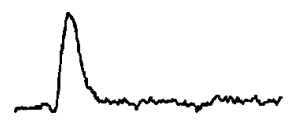

ii

PTMA

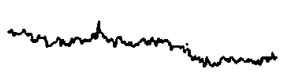

iii

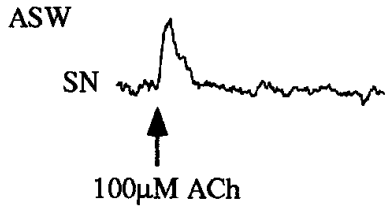

B

\section{Synaptic response}

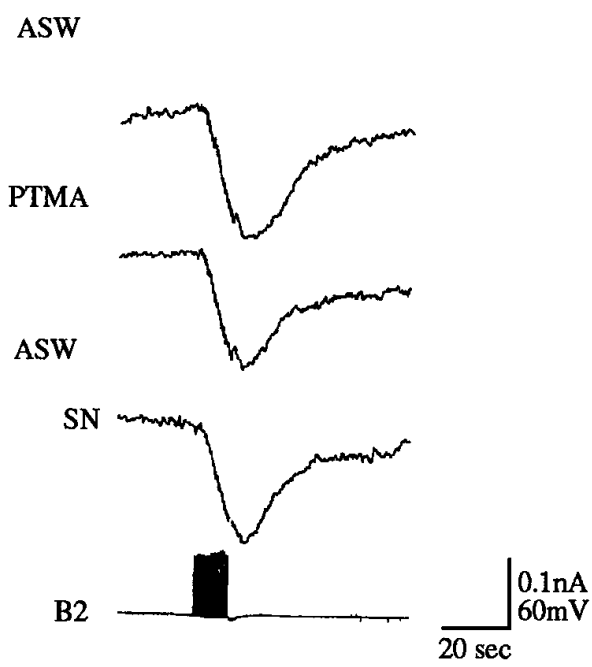

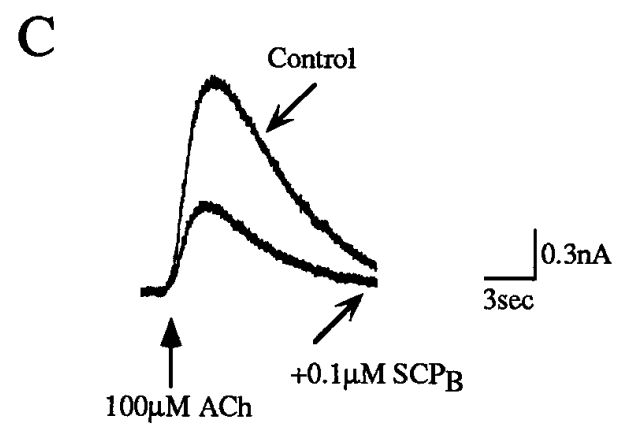

Figure 5. The slow synaptic current induced by B2 stimulation does not involve the release of ACh. $A i$, In a B2 $\rightarrow$ sensory neuron synapse, the puffed application of $100 \mu \mathrm{M}$ ACh onto the somata of the sensory neuron evoked an outward current. Aii, This current was blocked in the presence of $500 \mu \mathrm{M}$ PTMA, a cholinergic antagonist. Aiii, After washout of PTMA, the response to ACh was observed again. Bi, In the same synaptic pair, stimulation of B2 at $2 \mathrm{~Hz}$ for $10 \mathrm{sec}$ evoked a slow inward current in the sensory neuron. Bii, This current was not affected by the presence of $500 \mu \mathrm{M}$ PTMA. Biii, The synaptic current remained stable after washout of the PTMA. The sensory neuron was voltage-clamped at $-40 \mathrm{mV}$ throughout. The notch in the synaptic current reflects coupling between the pre- and postsynaptic electrodes (individual transients are not visible because of filtering). $C$, In an isolated sensory neuron, the outward current evoked by a 100 msec puff of $100 \mu \mathrm{M}$ ACh (Control) was reduced in the presence of $0.1 \mu \mathrm{M} \mathrm{SCP}_{\mathrm{B}}$. The sensory neuron was voltaged-clamped at a holding potential of $-40 \mathrm{mV}$.

likely is attributable to the secretion of ACh and does not involve a significant SCP-dependent component.

\section{Presynaptic injection of tetanus toxin inhibits the release of both ACh and the SCPs}

Tetanus toxin has been shown to cleave Aplysia synaptobrevin (Yamasaki et al., 1994) and to inhibit the release of ACh from Aplysia neurons in situ (Mochida et al., 1989; Schiavo et al., 1992). We observed similar effects of tetanus toxin light chain on the release of ACh from B2 (Fig. 7Ai). After control postsynaptic currents were recorded, the toxin was injected into the presynaptic B2 neuron. To ensure that inhibition did not occur simply as a result of transmitter depletion, we stored the synaptic pairs in low $\mathrm{Ca}^{2+} /$ high $\mathrm{Mg}^{2+} \mathrm{ASW}$ to prevent secretion. Six to eight hours later the postsynaptic response to single $\mathrm{B} 2$ action potentials again was recorded in nASW at the same synapse. In the experiment shown in Figure $7 \mathrm{Ai}$, the synaptic current was eliminated after tetanus toxin injection. In a series of experiments toxin injection reduced the postsynaptic current to $8 \pm 9 \%$ of the preinjected value (mean $\pm \mathrm{SD}, n=4)$.
As a control for any nonspecific changes in transmission after intracellular injection, we also tested the effects of injecting a mutated tetanus toxin in which a glutamate in the zinc-binding domain had been replaced with a glutamine. This mutant is unable to digest Aplysia synaptobrevin (Yamasaki et al., 1994). Presynaptic injection of this protein did not inhibit secretion of ACh over the same time course $(98 \pm 54 \%$ of the preinjection value, mean $\pm \mathrm{SD}, n=4$; the raw traces from one experiment are shown in Fig. 7Aii). Comparing the effects of the two treatments indicated that the inhibition seen with tetanus toxin light chain was significant (Fig. $7 C ; p<0.02$ ).

After confirming that tetanus toxin inhibits the release of ACh from synapses in vitro, we then examined the effect of injecting the light chain of tetanus toxin on the release of the SCPs. In preliminary experiments we noted that the result of the toxin injection tended to vary with the distance between the pre- and postsynaptic recording sites. Thus, to standardize the distance between the point of injection and the site of action, we measured peptide release, using soma $\rightarrow$ soma synapses made from presynaptic B1 or 

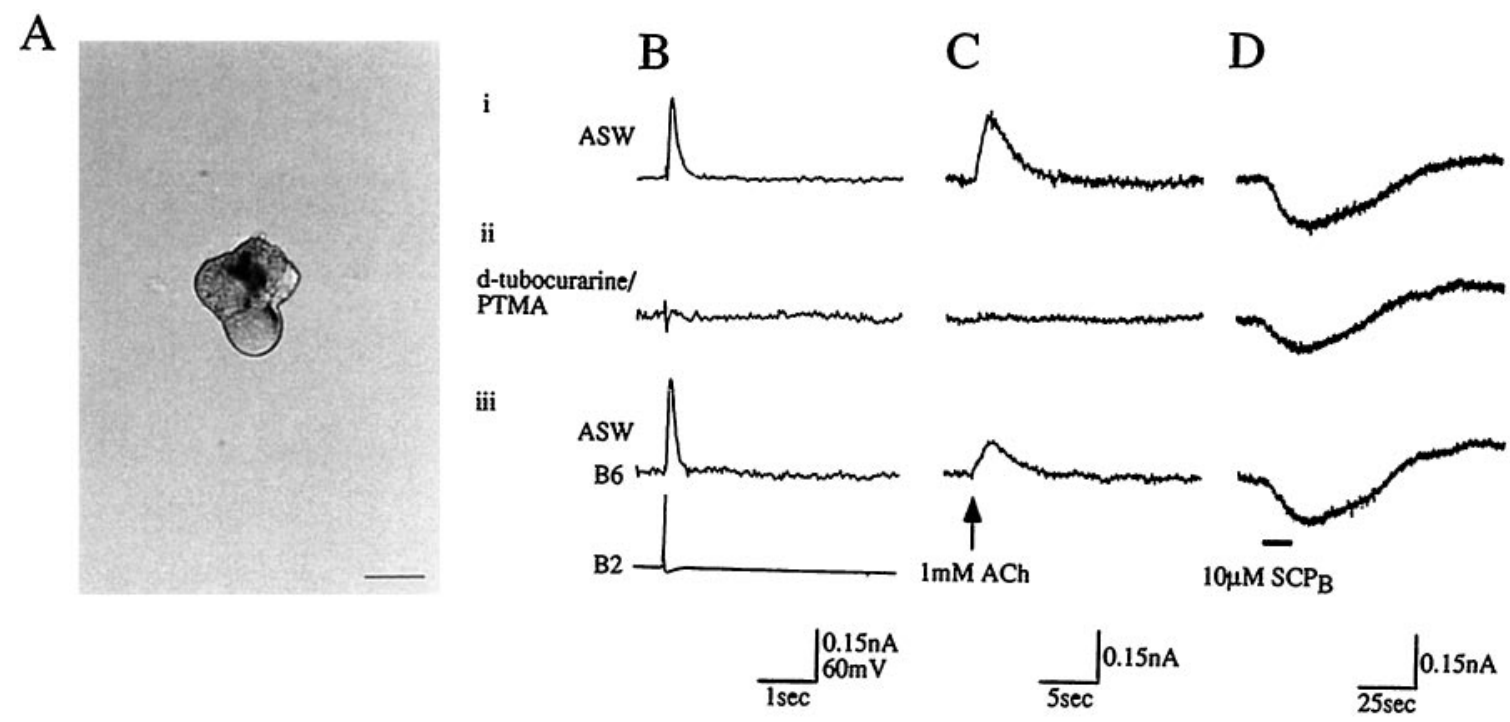

Figure 6. Release of ACh from B2 can be detected with B6 as the postsynaptic neuron. A, Bright-field image of a presynaptic B2 neuron and a postsynaptic B6 neuron combined in a soma $\rightarrow$ soma configuration. The B2 neuron is at lower right. The stumps projecting from both neurons are the remains of the primary neurites. Scale bar, $80 \mu \mathrm{m}$. Bi, A single action potential in B2 evoked a rapid outward current in the postsynaptic B6 neuron, which was voltage-clamped at $-40 \mathrm{mV}$. Bii, The outward current was blocked in the presence of the cholinergic antagonists D-tubocurarine and PTMA (100 $\mu \mathrm{M}$ and $500 \mu \mathrm{M}$, respectively). Biii, After washout of the antagonists, the outward current could be elicited again. Ci, The puffed application of $1 \mathrm{~mm}$ ACh onto B6 evoked an outward current. Cii, The current was blocked in the presence of D-tubocurarine and PTMA. Ciii, The current recovered after washout of the antagonists. $D i$, Bath application of $10 \mu \mathrm{M} \mathrm{SCP}{ }_{\mathrm{B}}$ evoked a slow biphasic current in the B6 neuron. Dii, The current was not markedly affected by the presence of D-tubocurarine and PTMA. Diii, The current remained stable after washout of the antagonists. All recordings are from the same cell pair. B2 was held at $-40 \mathrm{mV}$ throughout, except when stimulated to fire in $B$.

B2 neurons and single postsynaptic sensory neurons. Six to eight hours after injection of toxin, the slow synaptic current was reduced to $19 \pm 34 \%$ of the preinjection value (mean $\pm \mathrm{SD}, n=$ $6)$. In four of the six synaptic pairs, transmission was effectively eliminated (see Fig. 7Bi). Tetanus toxin injection inhibited the release of peptide that was induced either by single (Fig. 7Bi) or multiple action potentials (data not shown). Again, as a control for any nonspecific changes resulting from the injection, we also injected the inactive tetanus toxin mutant. After injection the slow synaptic current was $92 \pm 22 \%$ of the preinjection value (mean \pm $\mathrm{SD}, n=4$; an example of one experiment is shown in Fig. 7Bii). Comparing the effects of the two treatments indicated that the inhibition seen with tetanus toxin was significant (Fig. $7 C ; p<$ 0.01). We conclude that tetanus toxin inhibits the secretion of peptide transmitters, in addition to classical transmitters, from B1 and $\mathrm{B} 2$ neurons.

\section{DISCUSSION}

We have developed two synaptic preparations in which it is possible to monitor the release of a peptide and a classical transmitter from a single presynaptic neuron and have tested the role of synaptobrevin in transmitter release along both pathways.

Using the B1 and B2 neurons, which synthesize and release the SCPs (Lloyd et al., 1986; Whim et al., 1992), we have constructed a peptidergic synapse in vitro that used a sensory neuron as a postsynaptic detector for the SCPs. Five lines of evidence indicate that transmission is attributable to the release of the SCPs at this synapse. First, the synaptic current and the $\mathrm{SCP}_{\mathrm{B}}$-induced current have a prolonged time course, are inward at $-40 \mathrm{mV}$, and are associated with an apparent decrease in membrane conductance. Second, the voltage dependence and null potential of the synaptic- and peptide-induced currents are very similar. Third, because antagonists for most neuropeptide receptors (including the SCPs) are not available, we used a desensitization protocol to block the function of the postsynaptic SCP receptors. When the SCP receptors had been desensitized, we were unable evoke the synaptic current. Fourth, both stimulation of the B1,2 neuron and $\mathrm{SCP}_{\mathrm{B}}$ application produced an antiaccommodatory effect on the postsynaptic sensory neuron. Finally, although B2 is a combined cholinergic/peptidergic neuron, the slow synaptic current did not seem to involve the release of $\mathrm{ACh}$, because a cholinergic antagonist that blocked the effect of ACh on the postsynaptic neuron was without effect on the synaptic current. These five lines of evidence all point to the conclusion that the synaptic current is at least partially (and maybe wholly) attributable to the release of the SCPs.

Because B2 also synthesizes ACh (Lloyd et al., 1985), we also were able to detect the release of this classical transmitter from neuron B2 by using a different postsynaptic detector neuron. The outward synaptic current that we observed in these synapses likely is attributable to the secretion of $\mathrm{ACh}$, because it was mimicked by exogenous ACh (but not the SCPs) and was blocked completely by a cholinergic antagonist.

We have demonstrated that the synaptic vesicle protein synaptobrevin is required for the synaptic release of neuropeptides. The presynaptic injection of tetanus toxin, a metalloprotease that selectively digests synaptobrevin, inhibited the release of both the SCPs and ACh. Injection of a mutated toxin, which does not digest synaptobrevin, did not depress the release of either ACh or the SCPs. Thus a synaptobrevin-like protein plays an important role in the secretion of both clear vesicles and large dense core granules. These data are in agreement with the emerging picture that the secretion of many vesicle types share common proteins (Martin, 1994; Rothman, 1994). Synaptobrevin, first identified as a component of synaptic vesicles, recently has been localized to 
A
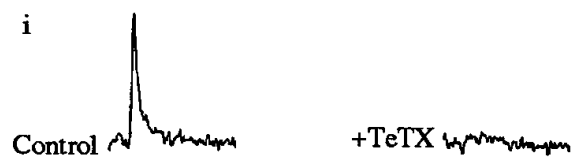

B

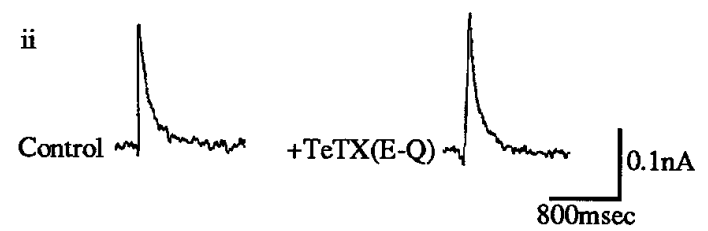

i
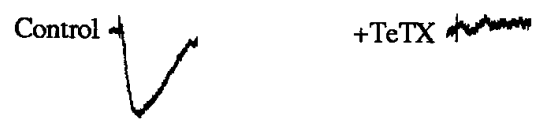

ii

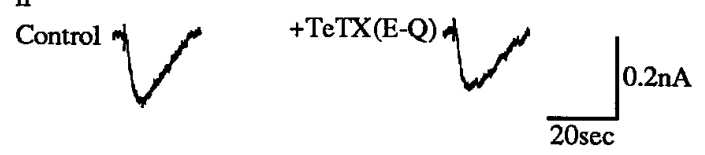

C

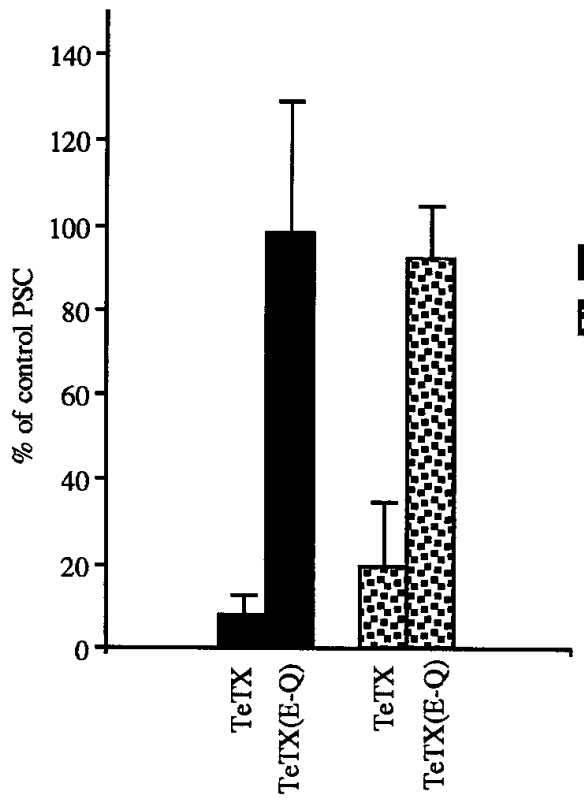

Figure 7. Tetanus toxin inhibits the release of ACh and the SCPs. A, ACh release was monitored as the amplitude of the postsynaptic current at a holding voltage of $-40 \mathrm{mV}$ (in neuron B3 in these examples), which was evoked by a $\mathrm{B} 2$ action potential before and $6-8 \mathrm{hr}$ after injection into the presynaptic neuron of either $(A i)$ tetanus toxin light chain $(T e T X)$ or $(A i i)$ an inactive mutant $[\operatorname{TeTX}(E-Q)] . B$, SCP release was monitored as the amplitude of the inward current evoked in the postsynaptic sensory neuron by stimulation of the presynaptic B2 neuron (in these examples) before and $6-8 \mathrm{hr}$ after injection into the presynaptic neuron of either $(B i)$ tetanus toxin light chain $(T e T X)$ or $(B i i)$ an inactive mutant $[T e T X(E-Q)]$. The synaptic current was evoked by a single action potential in these examples. The holding voltage was $-40 \mathrm{mV}$ in $B i$ and $-35 \mathrm{mV}$ in Bii. C, Group data indicate that the release of the SCPs and ACh was inhibited significantly by tetanus toxin light chain $[p<0.02$ for ACh release, $p<$ 0.01 for SCP release; inhibition was measured by comparing the effect of $T e T x$ and $T e T X(E-Q)$ injections]. Values are mean \pm SD $(n=4-6$ for each treatment). the dense core granules of PC12 cells, a neuroendocrine cell line (Papini et al., 1995), and is involved in secretion of norepinephrine from permeabilized PC12 cells (Lomneth et al., 1991). The precise role of synaptobrevin is not known, but because vesicles seem to dock normally in its absence, it has been suggested that it is involved in evoked vesicle fusion at a point downstream from docking (Hunt et al., 1994).

We found that peptide release often could be evoked with a single action potential. This agrees with previous data that the release of radiolabeled SCPs from B1 and B2 is linearly dependent on the spike number (Whim and Lloyd, 1994). Thus, contrary to a widespread assumption, the secretion of neuropeptides does not necessarily require high frequency bursts of action potentials. This observation is unlikely to be an artifact of cell culture, because the frequency characteristics of SCP release from another Aplysia motor neuron, B15, are very similar in situ and in culture (Whim and Lloyd, 1994). Instead, the parameters controlling the release of peptides may vary from cell to cell. For example, neurons B1 and B2, which fire at low frequencies in the behaving animal (Lloyd et al., 1988), can release the SCPs with a single action potential (see Results), whereas neuron B15, which fires at up to $12 \mathrm{~Hz}$ in the behaving animal (Cropper et al., 1990a,b), only releases the SCPs when firing at a relatively high frequency during long-duration bursts (Whim and Lloyd, 1989, 1990; Cropper et al., 1990b). This diversity influences the types of transmitter released. Like B2, neuron B15 is a cholinergic neuron, and release of ACh occurs with each action potential (Cohen et al., 1978). Thus when firing slowly, B15 seems to function as a purely cholinergic neuron and as a combined cholinergic-peptidergic neuron when firing rapidly. In contrast, neuron B2 may function as a combined cholinergic-peptidergic neuron at all frequencies.

It is believed that in contrast to the vesicles that contain classical neurotransmitters, peptide-containing dense core granules are not released at specialized sites (but see Schroeder et al., 1994). This has led to the proposal that only with multiple action potentials does calcium rise to sufficiently high levels away from the vicinity of the plasma membrane to trigger the release of neuropeptides. Our finding that the SCPs may be released with a single action potential indicates that some dense core granules could be functionally docked at the presynaptic membrane (although this needs to be examined at the EM level). This suggestion is consistent with the observation that a subset of dense core granules in pituitary cells can be released rapidly (Thomas et al., 1993).

Although neuron B2 is a cholinergic neuron and sensory neurons express $\mathrm{ACh}$ receptors, we could not detect a cholinergic component in the synaptic response when these neurons were paired. One explanation is that the ACh receptor is not clustered at postsynaptic sites. These neurons seem to express only one type of ACh receptor, which is blocked by the antagonist PTMA. In contrast, B6 neurons, which readily form cholinergic synapses with B2 neurons, express at least two types of receptors, one of which is blocked by D-tubocurarine and the other by PTMA. Only the D-tubocurarine receptors seemed to be localized at synaptic sites, because the synaptic response could be blocked by D-tubocurarine alone. We also found that the synaptic current reversed close to $-60 \mathrm{mV}$ (data not shown) as expected for the D-tubocurarinesensitive ACh receptor (Kehoe, 1972b). It is likely, therefore, that only the D-tubocurarine receptors cluster under the sites of transmitter release.

A second factor that may contribute to the absence of a cholinergic synapse between a B1,2 neuron and a sensory neuron is a 
reduction in the sensitivity of the target PTMA-ACh receptors in the presence of the SCPs. This follows from the observation that the outward current evoked by the local application of ACh was reduced when the SCPs were coapplied. A similar mechanism operates at some vertebrate receptors in which calcitonin generelated peptide has been shown to desensitize nicotinic ACh receptors (Mulle et al., 1988).

Some neurons require a signal from their in vivo target before they become competent to release transmitter (see Haydon and Drapeau, 1995), whereas others can be induced to do so when their initial axon segments are manipulated into close proximity (Hawver and Schacher, 1993). The area of contact between two cells may be important for the stabilization of classical transmitter synapses in vitro (Evers et al., 1989). Whether similar considerations apply to the formation of peptidergic synapses is not known. A specialized area of contact, however, seems not to be required. For example, in the bullfrog the release of luteinizing hormone-releasing hormone (LHRH) from preganglionic neurons is detected by cells that are not anatomically close to the LHRH-containing nerve terminals (Jan and Jan, 1982). The detector neuron simply may record the spillover of peptide into the extracellular space.

Although the mechanism by which the SCPs evoked a postsynaptic inward current was not the focus of this study, other work has indicated that the SCPs inhibit a resting potassium current (probably the "S" current) in sensory neurons (Baxter and Byrne, 1989). Nevertheless the reversal potential of approximately -54 $\mathrm{mV}$ that we observed for both the synaptic- and $\mathrm{SCP}_{\mathrm{B}}$-induced currents does not correspond to the equilibrium potential for potassium. Possibly additional ionic currents are modulated. Other workers, however, have shown that the serotonindependent depolarization of sensory neurons, which also involves a modulation of the $\mathrm{S}$ channel, approaches the null current at approximately $-45 \mathrm{mV}$. This has been explained by the strong outward rectification of the S current (Siegelbaum et al., 1982; Pollock et al., 1985). We likewise observed a rectification in the synaptic- and $\mathrm{SCP}_{\mathrm{B}}$-induced currents in some experiments.

In conclusion, we have used two in vitro synapses to demonstrate the release of a neuropeptide and a classical transmitter from the same presynaptic neuron. A synaptobrevin-like molecule is involved in the two forms of neurotransmission, and the release of both types of transmitter can occur with a single action potential. This preparation may be useful in examining further the role of other vesicular and plasma membrane molecules in the release of neuropeptides.

\section{REFERENCES}

Abrams TW, Castellucci VF, Camardo JS, Kandel ER, Lloyd PE (1984) Two endogenous neuropeptides modulate the gill and siphon withdrawal reflex in Aplysia by presynaptic facilitation involving cAMPdependent closure of a serotonin-sensitive potassium channel. Proc Natl Acad Sci USA 81:7956-7960.

Anderson MJ, Cohen MW, Zorychta E (1977) Effects of innervation on the distribution of acetylcholine receptors on cultured muscle cells. J Physiol (Lond) 268:731-756.

Baxter DA, Byrne JH (1989) Serotonergic modulation of two potassium currents in the pleural sensory neurons of Aplysia. J Neurophysiol 62:665-679.

Bruns D, Jahn R (1995) Real-time measurement of transmitter release from single synaptic vesicles. Nature 377:62-65.

Cain CC, Trimble WS, Lienhard GE (1992) Members of the VAMP family of synaptic vesicle proteins are components of glucose transporter-containing vesicles from rat adipocytes. J Biol Chem 267:11681-11684.

Church PJ, Whim MD, Lloyd PE (1993) Modulation of neuromuscular transmission by conventional and peptide transmitters released from excitatory and inhibitory motor neurons in Aplysia. J Neurosci 13:2790-2800.

Cohen JL, Weiss KR, Kupfermann I (1978) Motor control of buccal muscles in Aplysia. J Neurophysiol 41:157-180.

Cropper EC, Kupfermann I, Weiss KR (1990a) Differential firing patterns of the peptide-containing motor neurons B15 and B16 during feeding behavior in Aplysia. Brain Res 522:176-179.

Cropper EC, Price D, Tenenbaum R, Kupfermann I, Weiss KR (1990b) Release of peptide cotransmitters from a cholinergic neuron under physiological conditions. Proc Natl Acad Sci USA 87:933-937.

Dayanthi G, Stecher B, Hohne-Zell B, Yamasaki S, Binz T, Weller U, Niemann H, Gratzl M (1994) Exploring the functional domain and the target of the tetanus toxin light chain in neurohypophysial terminals. Neuroscience 58:423-431.

De Camilli P, Jahn R (1990) Pathways to regulated exocytosis in neurons. Annu Rev Physiol 52:625-645.

Dodge Jr FA, Rahamimoff R (1967) Co-operative action of calcium ions in transmitter release at the neuromuscular junction. J Physiol (Lond) 193:419-432.

Dutton D, Dyball REJ (1979) Phasic firing enhances vasopressin release from the rat neurohypophysis. J Physiol (Lond) 290:433-440.

Elferink LA, Trimble WS, Scheller RH (1989) Two vesicle-associated membrane protein genes are differentially expressed in the rat central nervous system. J Biol Chem 264:11061-11064.

Evers J, Laser M, Sun Y-A, Poo M-M (1989) Studies of nerve-muscle interactions in Xenopus cell culture: analysis of early synaptic currents. J Neurosci 9:1523-1539.

Gardner D (1971) Bilateral symmetry and interneuronal organization in the buccal ganglia of Aplysia. Science 173:550-553.

Hawver DB, Schacher S (1993) Selective fasiculation as a mechanism for the formation of specific chemical connections between Aplysia neurons in vitro. J Neurobiol 24:368-383.

Haydon PG (1988) The formation of chemical synapses between cellcultured neuronal somata. J Neurosci 8:1032-1038.

Haydon PG, Drapeau P (1995) From contact to connection: early events during synaptogenesis. Trends Neurosci 18:196-201.

Hunt JM, Bommert K, Charlton MP, Kistner A, Habermann E, Augustine GJ, Betz H (1994) A post-docking role for synaptobrevin in synaptic vesicle fusion. Neuron 12:1269-1279.

Jan LY, Jan YN (1982) Peptidergic transmission in sympathetic ganglia of the frog. J Physiol (Lond) 327:219-246.

Kehoe JS (1972a) Three acetylcholine receptors in Aplysia neurones. J Physiol (Lond) 225:115-146.

Kehoe JS (1972b) Ionic mechanisms of a two-component cholinergic inhibition in Aplysia neurones. J Physiol (Lond) 225:85-114.

Klein M, Hochner B, Kandel ER (1986) Facilitatory transmitters and cAMP can modulate accommodation as well as transmitter release in Aplysia sensory neurons: evidence for parallel processing in a single cell. Proc Natl Acad Sci USA 83:7994-7998.

Kupfermann I (1991) Functional studies of cotransmission. Physiol Rev 71:683-732.

Lloyd PE, Mahon AC, Kupfermann I, Cohen JL, Scheller RH, Weiss KR (1985) Biochemical and immunocytological localization of molluscan small cardioactive peptides (SCPs) in the nervous system of Aplysia californica. J Neurosci 5:1851-1861.

Lloyd PE, Schacher S, Kupfermann I, Weiss KR (1986) Calciumdependent release of neuropeptides during intracellular stimulation of single identified Aplysia neurons in culture. Proc Natl Acad Sci USA 83:9794-9798.

Lloyd PE, Kupfermann I, Weiss KR (1988) Central peptidergic neurons regulate gut motility in Aplysia. J Neurophysiol 59:1613-1626.

Lomneth R, Martin TFJ, DasGupta BR (1991) Botulinum neurotoxin light chain inhibits norepinephrine secretion in PC12 cells at an intracellular membranous or cytoskeletal site. J Neurochem 57:1413-1421.

Martin TFJ (1994) The molecular machinery for fast and slow neurosecretion. Curr Opin Neurobiol 4:626-632.

Mochida S, Poulain B, Weller U, Habermann E, Tauc L (1989) Light chain of tetanus toxin intracellularly inhibits acetylcholine release at neuro-neuronal synapses, and its internalization is mediated by heavy chain. FEBS Lett 253:47-51.

Mulle C, Benoit P, Roa M, Changeux J-P (1988) Calcitonin gene-related peptide enhances the rate of desensitization of the nicotinic acetylcholine receptor in cultured mouse muscle cells. Proc Natl Acad Sci USA 85:5728-5732. 
Niemann H, Blasi J, Jahn R (1994) Clostridial neurotoxins: new tools for dissecting exocytosis. Trends Cell Biol 4:179-185.

Ocorr K, Byrne JH (1985) Membrane responses and changes in cAMP levels in Aplysia sensory neurons produced by serotonin, tryptamine, FMRFamide, and small cardioactive peptide $\mathrm{B}\left(\mathrm{SCP}_{\mathrm{B}}\right)$. Neurosci Lett 55:113-118.

Papini E, Rossetto O, Cutler DF (1995) Vesicle-associated membrane protein (VAMP)/synaptobrevin-2 is associated with dense core secretory granules in $\mathrm{PC12}$ neuroendocrine cells. J Biol Chem 270:1332-1336

Peng Y-Y, Horn JP (1991) Continuous repetitive stimuli are more effective than bursts for evoking LHRH release in bullfrog sympathetic ganglia. J Neurosci 11:85-95.

Peng Y-Y, Zucker RS (1993) Release of LHRH is linearly related to the time integral of presynaptic $\mathrm{Ca}^{2+}$ elevation above a threshold level in bullfrog sympathetic ganglia. Neuron 10:465-473.

Penner R, Neher E, Dreyer F (1986) Intracellularly injected tetanus toxin inhibits exocytosis in bovine chromaffin cells. Nature 324:76-78.

Pollock JD, Bernier L, Camardo JS (1985) Serotonin and cyclic adenosine $3^{\prime}: 5^{\prime}$-monophosphate modulate the potassium current in tail sensory neurons in the pleural ganglion of Aplysia. J Neurosci 5:1862-1871.

Reed W, Weiss KR, Lloyd PE, Kupfermann I, Chen M, Bailey CH (1988) Association of neuroactive peptides with the protein secretory pathway in identified neurons of Aplysia californica: immunolocalization of $\mathrm{SCP}_{\mathrm{A}}$ and $\mathrm{SCP}_{\mathrm{B}}$ to the contents of dense-core vesicles and the trans face of the Golgi apparatus. J Comp Neurol 272:358-369.

Rothman JE (1994) Mechanisms of intracellular protein transport. Nature 372:55-63.

Schacher S, Proshansky E (1983) Neurite regeneration by Aplysia neurons in dissociated cell culture: modulation by Aplysia hemolymph and the presence of the initial axon segment. J Neurosci 3:2403-2413.

Schiavo G, Benfenati F, Poulain B, Rossetto O, de Laureto P, DasGupta BR, Montecucco C (1992) Tetanus and botulinum B neurotoxins block neurotransmitter release by proteolytic cleavage of synaptobrevin. Nature 359:832-835.
Schroeder TJ, Jankowski JA, Senyshyn J, Holz RW, Wrightman RM (1994) Zones of exocytotic release on bovine medullary cells in culture. J Biol Chem 269:17215-17220.

Siegelbaum SA, Camardo JS, Kandel ER (1982) Serotonin and cyclic AMP close single $\mathrm{K}^{+}$channels in Aplysia sensory neurones. Nature 299:413-417.

Sollner T, Whiteheart SN, Brunner M, Erdjument-Bromage H, Geromanos S, Tempst P, Rothman JE (1993) SNAP receptors implicated in vesicle targeting and fusion. Nature 362:318-324.

Thomas P, Wong JG, Almers W (1993) Millisecond studies of secretion in single rat pituitary cells stimulated by flash photolysis of caged $\mathrm{Ca}^{2+}$. EMBO J 12:303-306.

Trimble WS, Cowan DM, Scheller RH (1988) VAMP-1: a synaptic vesicle-associated integral membrane protein. Proc Natl Acad Sci USA 85:4538-4542.

Whim MD, Lloyd PE (1989) Frequency-dependent release of peptide cotransmitters from identified cholinergic motor neurons in Aplysia. Proc Natl Acad Sci USA 86:9034-9038.

Whim MD, Lloyd PE (1990) Neuropeptide cotransmitters released from an identified cholinergic motor neuron modulate neuromuscular efficacy in Aplysia. J Neurosci 10:3313-3322.

Whim MD, Lloyd PE (1992) Modulation of peptide release from single identified Aplysia neurons in culture. J Neurosci 12:3545-3553.

Whim MD, Lloyd PE (1994) Differential regulation of the release of the same peptide transmitters from individual identified motor neurons in culture. J Neurosci 14:4244-4251.

Willard AL (1990) A vasoactive intestinal peptide-like cotransmitter at cholinergic synapses between rat myenteric neurons in cell culture. J Neurosci 10:1025-1034.

Yamasaki S, Hu Y, Binz T, Kalkuhl A, Kurazono H, Tamura T, Jahn R, Kandel E, Niemann H (1994) Synaptobrevin/vesicle-associated membrane protein (VAMP) of Aplysia californica: structure and proteolysis by tetanus toxin and botulinum neurotoxins type D and F. Proc Natl Acad Sci USA 91:4688-4692. 